\title{
Rebelde: estratégia mercadológica de rizoma e tática discursiva de árvore
}

João Anzanello Carrascoza

Doutor e mestre em Ciência da Comunicaşão pela ECA-USP, onde é professor titular no curso de Publicidade e Propaganda, e docente do Programa de Mestrado em Comunicação e Práticas de Consumo da ESPM.

E-mail: jcarrascoza@espm.br

Juliana de Assis Furtado

Graduada em Publicidade e Propaganda pela ECA-USP e mestranda do Programa de Mestrado em Comunicação e Práticas de Consumo da ESPM.

E-mail: juliana_furtado@hotmail.com

Barracas de camping e dezenas de pais e filhos de prontidão no perímetro do estádio do Morumbi, em São Paulo, à espera do início da venda de ingressos, que só aconteceria dali a três dias. Se, para muitos transeuntes, a cena revelava uma euforia exagerada, para aqueles fãs era algo natural - e, para nós, mais uma prova do impacto do fenômeno comunicacional chamado Rebelde. $\mathrm{O}$ que poderia não passar de mais uma telenovela mexicana importada pelo SBT tornou-se rapidamente uma sensação no Brasil, à semelhança do que já vinha acontecendo pelo mundo.

Essa aglomeração de pessoas era uma pequena parte dos 40 mil espectadores que assistiriam, em outubro de 2006, à segunda apresentação da banda $R B D$ na cidade. $\mathrm{O}$ grupo trazia como integrantes seis alunos protagonistas da telenovela, da qual é um dos inúmeros desdobramentos mercadológicos.

A história teve início na Argentina, com a novela Rebelde Way. De 2002 a 2004, período em que esteve no ar, alcançou sucesso extraordinário no país e fora dele. A banda Erreway, nascida dentro da trama ficcional e transferida para palcos reais, conquistou milhões de fãs, provocando tumulto por onde passou.

Em 2004, os direitos de Rebelde Way foram vendidos à Televisa, que realizou sua versão no México, seguindo o roteiro original com poucas alterações. A telenovela passou a chamar Rebelde e a banda, $R B D$. A essência era a mesma: jovens que vivem o desenrolar de seus conflitos num ambiente de elite, o aristocrático colégio Elite Way School. Enquanto no enredo original os protagonistas argentinos tinham idade entre 15 e 19 anos, em Rebelde a faixa etária subiu, 
variando entre 18 e 21 anos - o que permitiu maior erotização na narrativa. A mudança revela, por parte de seus produtores, a perfeita noção de target, de público-alvo, que, bem definido em publicidade, pode gerar maior identificação com os telespectadores e ampliar o consumo.

Transmitida no Brasil a partir de agosto de 2005, a telenovela repetiu a popularidade alcançada em mais de 70 países em que foi ao ar, chegando a atingir a vice-liderança no seu horário ${ }^{1}$ e gerando muito mais do que fãs enlouquecidos. Além da banda $R B D$, a qual vem fazendo turnês por preços nada módicos - no show realizado em abril de 2007, os ingressos variavam de $\mathrm{R} \$$ 100,00 a $\mathrm{R} \$ 500,00$-, Rebelde contabiliza seis álbuns (três deles com versões em português), quatro DVDs, uma série de desenho animado, revistas e pôsteres, álbuns de figurinhas, bonecas, materiais escolares, tênis, sandálias, roupas, fantasias, telefone celular, jogos, câmeras digitais, laptops, cosméticos e gomas de mascar.

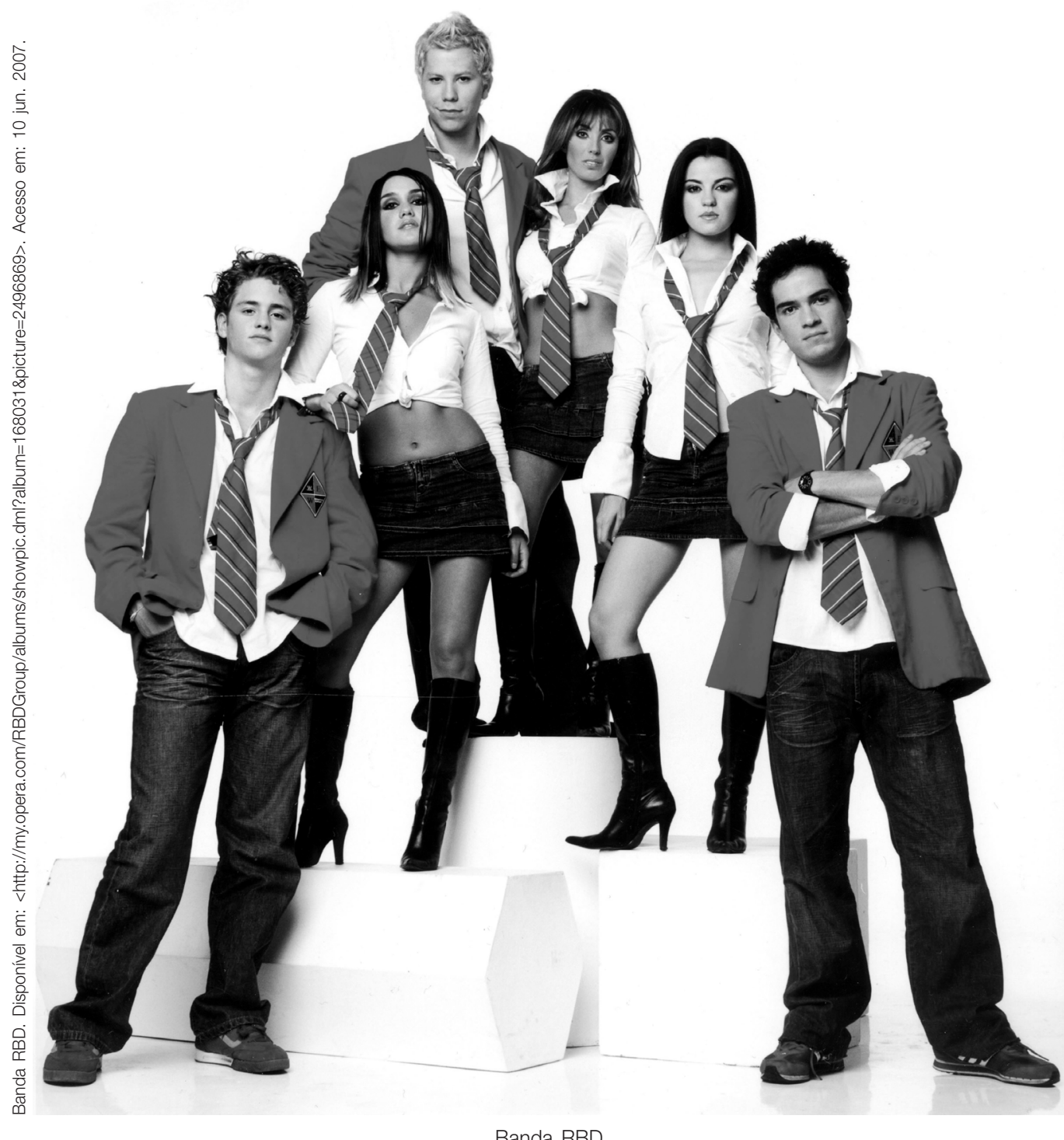

1. IBOPE sobe e Rebelde vira melhor novela do país. Folha Online, 28 mar. 2006. Disponível em $<$ http://www1.folha.uol. com.br/folha/ilustrada/ul t90u59188.shtml>. Acesso em: 13 maio 2007

Banda RBD 
Em agosto de 2006, estimava-se que a marca movimentaria $\mathrm{R} \$ 200$ milhões em vendas no varejo até o fim daquele ano. Na época, havia 27 contratos fechados para licenciamento de Rebelde, o que resultaria em 500 itens nas prateleiras até setembro. Em três meses, 35 milhões de figurinhas haviam sido vendidas pela Panini e 10 milhões de revistas pela Online Editora ${ }^{2}$.

Em março de 2007, estreou no México a série de TV RBD La Familia, num formato que mescla ficção com a vida real dos atores. A banda conquistou neste mesmo ano um canal de televisão, no sistema via satélite Sky: o Canal Rebelde, criado para apoiar a série La Familia, e que exibirá também a reprise da telenovela teen, shows já gravados e novos espetáculos do RBD. Os projetos incluem ainda para 2007 um longa-metragem e o início das operações da Fundação Salva-me (Fundación Salvame), uma instituição para apoiar e retirar crianças da rua.

Feito esse necessário intróito, vamos abordar Rebelde e seus derivados por meio do conceito de árvore e de rizoma, aproximando-o, posteriormente, ao universo discursivo da publicidade.

Em Mil Platôs: Capitalismo e Esquizofrenia ${ }^{3}$, Gilles Deleuze e Félix Guattari, refletindo especificamente sobre a cultura livresca, diferenciam o livro-raiz, que segue uma lógica binária e não admite multiplicidade, do livro-rizoma, que, como haste subterrânea, tem nele mesmo formas muito diversas, desde sua extensão superficial ramificada em todos os sentidos até concreções em bulbos e tubérculos.

Aplicada essa diferenciação ao campo do pensamento e do conhecimento, os autores associam sua reprodução à maneira das árvores ou dos rizomas. A árvore obedece a uma ordem fixa, a da raiz, para crescer. Seu modelo é o da autoridade, do controle e da tradição, baseado, portanto, em hierarquia; enquanto o rizoma se espalha, desdobra-se, sem centro nem hierarquia. Orienta-se por princípios como o de conexão, heterogeneidade e multiplicidade, e assume configurações distintas, expandindo-se horizontalmente para todos os lados, interconectando-se por linhas de fuga.

Para Deleuze e Guattari, o modelo arborescente domina o pensamento europeu, ao passo que nas Américas o padrão de conhecimento é rizomático. Não é por acaso, podemos acrescentar, que Rebelde (e suas demais ramagens) tenha surgido em solo cultural americano, inicialmente na Argentina e, depois, no México.

Como estratégia de ficção, segue o mesmo caminho da literatura de alguns escritores americanos cujas obras foram pensadas por linhas de fuga, como Melville, Kerouac e Whitman; este último autor de Folhas de Relva, exemplo de livro-rizoma não apenas no título, mas em toda sua escritura.

Rodrigo Garcia Lopes, que traduziu Folhas de Relva para o português, afirma que elas cresceram pelo meio, enquanto eram elaboradas, em fragmentos: "Whitman passou 38 anos expandindo seu livro-relva, reformulando seções, incluindo linhas, reformatando poemas" . A obra "enfatiza o movimento, o momento presente, as linhas de fuga do pensamento não-linear" . Ou seja, "oferece um método de pensamento e vida que está sempre a caminho, em processo, oposto à fixidez e rigidez da árvore, que nasce e morre num mesmo lugar"6.
2. TEICH, Camila. Febre "Rebelde" invade prateleiras e movimenta setor de licenciamento. Gazeta Mercantil, São Paulo, p. C6, 9 ago. 2006.

3. DELEUZE, Gilles; GUATTARI, Félix. Mil platôs: capitalismo e esquizofrenia. Rio de Janeiro: Editora 34, 1995. v. 1.

4. LOPES, Rodrigo Garcia. Uma experiência de linguagem: Whitman e a primeira edição de FoIhas de Relva (1855). In: WHITMAN, Walt. Folhas de relva. São Paulo: Iluminuras, 2005. p. 312.

5. Ibid.

6. Ibid. 
7. CARRASCOZA, João A. Razão e sensibilidade no texto publicitário São Paulo: Futura, 2004. p. 31.

8. A HARD Day's Night (Os Reis dos lê lê lê). Direção de Richard Lester. Estados Unidos, 1964 (85 min).

9. YELLOW Submarine (Submarino Amarelo). Direção de George Dunning. Estados Unidos 1968 (90 min).

10. LET It Be (Sem tradução). Direção de Michael Lindsay-Hogg. Inglaterra, 1969 (32 $\mathrm{min})$.
Curiosamente, nessa sua obra rizomática, Whitman explora a técnica de catalogação, espécie de bricolagem, por meio da qual ele acumula uma imagem sobre a outra, enumerando as suas qualidades, como o faz o discurso publicitário apolíneo ${ }^{7}$ - fincado na razão -, que empilha os atributos do produto como uma lista de suas virtudes.

O rizoma é feito de platôs - e um platô é toda a multiplicidade conectável com outras hastes subterrâneas superficiais. Cada platô pode ser lido em qualquer posição e posto em relação com qualquer outro. E essa é a primeira aproximação que podemos fazer do sistema rizomático com a estratégia mercadológica de Rebelde. Cada produto que parte da telenovela, inclusive ela mesma, é um platô: a banda $R B D$, os álbuns de figurinhas, a Fundação Salva-me, o canal de TV, as revistas, os desenhos animados, as roupas, enfim, tudo o que arrolamos.

Mas, assim como existem os dois modelos distintos, pode haver estrutura de árvore - raízes - nos rizomas, formando nós arborescentes; e, por outro lado, também um galho de árvore pode brotar em rizoma.

Os Beatles, por exemplo, seguiram um modelo de árvore. Fundamentalmente, o quarteto de Liverpool se notabilizou pela música, sua manifestação artística-raiz. Os novos ramos de negócios surgidos, como os filmes dos quais participaram ( A Hard Days Night $t^{8}$, Yellow Submarine ${ }^{9}$, Let It Be ${ }^{10}$ ), respeitavam a um comando central - a expressão musical do grupo, instância máxima da hierarquia. Todos os subprodutos foram, e ainda são décadas depois do fim da banda, concebidos para divulgar as canções dos Beatles e o mundo de seus criadores. As várias tentativas de reconstituição da banda nos mostram a ação dos empuxos rizomáticos, possíveis de se manifestarem no centro dos modelos arbóreos.

Rebelde, por sua vez, desenvolve-se em platôs que se intercomunicam, não em produto, como os Beatles, que geraram subprodutos. A telenovela cresce por si mesma, embora divulgue o $R B D$; o $R B D$ faz shows, ocupando um espaço no mercado do show business, sem se descolar da telenovela, mas também sem ser caudatário dela. Assim os platôs se ligam, plugam-se.

Já no plano narrativo, as tramas e subtramas de Rebelde apresentam um mundo de conflitos pueris. A rebeldia se limita a provocações à ordem estabelecida, nunca a sua subversão, como, por exemplo, o strip-tease de Mia para se vingar do pai, que não comparece à cerimônia de fim de ano; o refrigerante que Roberta atira em Mia, quando esta vem lhe dar as boas-vindas; as atitudes de Roberta para esconder dos demais as muitas plásticas que sua mãe fez; o empurrão que Diego dá em Roberta, atirando-a ao mar, quando faziam um passeio de barco; a fúria de Roberta, que quebra o gravador quando Mia a impede de se integrar em seu grupo de coreografia; a manifestação encabeçada por Mia para que Vick, expulsa da escola, seja reincorporada.

O último episódio é emblemático: o protesto não é pela implosão da Elite Way School, que, na qualidade de aparelho ideológico do Estado, reproduz a ideologia dominante, mas justamente pela sua manutenção. A "rebeldia" em relação à escola se dá apenas na superfície, como, por exemplo, quando os alunos fogem das aulas para ir a baladas, ou no episódio em que enviam ao 
diretor um busto com uma bomba dentro, mas decidem recuperá-lo antes de sua explosão.

Como tática discursiva, portanto, a telenovela mostra tensões que são próprias de um mundo edulcorado e a atitude das personagens não transgride senão a aparência do construto social. Os rebeldes são jovens enquadrados pelos valores dominantes, que se arvoram em questionar as autoridades não para desafiá-las, mas para obter alguma vantagem própria. São, portanto, personagens que representam o indivíduo integrado, tão bem definido nesses versos da canção Rebelde sem causa ${ }^{11}$ da banda brasileira Ultraje a Rigor:

Minha mãe até me deu essa guitarra

Ela acha bom que o filho caia na farra

E o meu carro foi meu pai que me deu

Filho homem tem que ter um carro seu

Fazem questão que eu só ande produzido

Se orgulham de ver o filhinho tão bonito

Me dão dinheiro pra eu gastar com a mulherada

Eu realmente não preciso mais de nada

Meus pais não querem

Que eu fique legal

Meus pais não querem

Que eu seja um cara normal

Não vai dar, assim não vai dar

Como é que eu vou crescer sem ter com quem me revoltar

Não vai dar, assim não vai dar

Pra eu amadurecer sem ter com quem me rebelar

O faz-de-conta de Rebelde nos aproxima assim do pasteurizado, conservador e pleno de clichês discurso publicitário.

Valendo-se do apoio de teóricos como Brentano, Schaff, Lacan e Saussure, Tognolli alerta-nos para que "o uso de formas fixas, dos chavões, dos clichês, vai fraturando todo o sistema de conhecimento, da simbolização e da percepção"12.

Para Oliviero Toscani, publicitário outsider, a publicidade hegemônica, contra a qual ele se rebelou, promove alienação em sua narrativa. As crianças correm sempre alegres, os bebês são sempre lindos, os lençóis são de seda, o planeta é um reino sem rugas, sem sofrimento, sem morte. Só no território da propaganda são comuns cenas como essa: uma mãe com suas crianças,

[...] sem uma única estria, zero grama de celulite, vai cantarolando enquanto enrola numa fralda suas bundinhas roliças nunca sujas de cocô, e tem um cheirinho tão gostoso! Depois, oh, a bela fada loura e bem-feita de corpo! Ela lava o chão de ladrilhos dançando numa cozinha grande como o salão de um restaurante. Graças a um fabuloso pó, transforma montanhas de roupa branca imunda em pilhas e pilhas de roupas novinhas em folha. Milagre!, o sangue das regras tornase azulzinho e não suja mais suas calcinhas, azul como o céu através da janela, azul esmaltado como o xixi de seu neném que não foge nunca ${ }^{13}$.

Nas palavras de Baudrillard, é a função lúdica da publicidade, que nos oferece a tranqüilidade de uma imagem jamais negativa. "Somos sensíveis à
11. MOREIRA, Roger. Rebelde sem causa. Disponível em: <http://ultraje-a-rigor.letras.terra.com. $\mathrm{br} /$ letras/49198/>. Acesso em: 19 maio 2007.

12. TOGNOLLI, Claudio. A sociedade dos chavões. 2. ed. São Paulo: Escrituras, 2002. p. 34-35.

13. TOSCANI, Oliviero. A publicidade é um cadáver que nos sorri. 2. ed. Rio de Janeiro: Ediouro, 1996. p. 14. 
manifestação fantástica de uma sociedade capaz de ultrapassar a estrita necessidade dos produtos na superfluidade das imagens, somos sensíveis à sua virtude de espetáculo, de jogo, de encenação." ${ }^{14}$

Não obstante a crítica, também lugar-comum, de Toscani, o corpo nas peças publicitárias é de fato imaculado, sem imperfeições, coerente com a cultura narcisística da atual sociedade capitalista. E mesmo quando o modelo oficial de beleza é atacado, como no caso da campanha das loções Dove, da qual selecionamos o anúncio a seguir, a rebeldia é de fachada, advinda de um pensamento estratégico que desafia apenas o formato predominante da propaganda, mas nunca a própria propaganda.

No anúncio, vemos uma mulher com uma marca de cesariana no corpo segurando seu bebê. Jovem e bonita, ela visivelmente posa para a foto, e sorri, como se satisfeita com seu defeito, que é explorado de forma eufórica em seu depoimento:

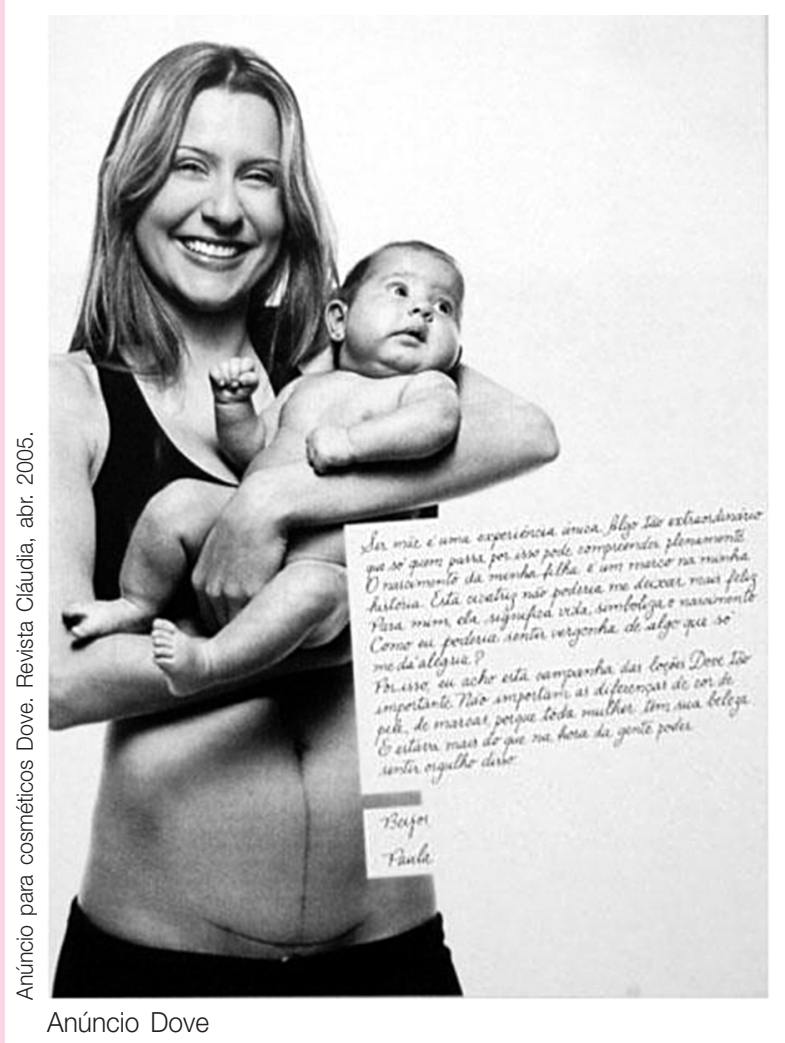

Ser mãe é uma experiência única. Algo tão extraordinário que só quem passa por isso pode compreender plenamente. O nascimento da minha filha é um marco na minha história. Esta cicatriz não poderia me deixar mais feliz. Para mim, ela significa nascimento. Como eu poderia sentir vergonha de algo que só me dá alegria? Por isso eu acho esta campanha das loções Dove tão importante. Não importam as diferenças de cor de pele, de marcas, porque toda mulher tem sua beleza. E estava mais do que na hora da gente poder sentir orgulho disso. Beijos, Paula.

O texto, autoritário e auto-referencial, é o testemunho, forjado ou não, de alguém que possui competência no assunto - uma mulher com cicatriz resultante da cirurgia cesariana -, que, além de usar as loções Dove, também elogia a campanha ousada da marca. O slogan "Toda mulher é bonita quando sua pele é bem tratada” se incumbe de relativizar seu estigma. Slogan que, nas narrativas publicitárias dionisíacas, focadas na emoção, como essa, correspondem sempre à moral da história contada ${ }^{15}$.

Essa referencialidade pode ser vista, da mesma maneira, nos platôs de $R e^{-}$

14. BAUDRILLARD, Jean. O sistema dos objetos. São Paulo: Perspectiva, 1993. p. 181. (Debates).

15. CARRASCOZA, op. cit. belde - a banda RBD, o álbum de figurinhas do grupo, os produtos licenciados -, uns fazendo menções aos outros, este à telenovela, aquele à banda $R B D$, a banda aos produtos, criando, assim, uma intricada rede de conexão. 
Como a estratégia paternal que protegia Buda do contato com a dor e com a precariedade da condição humana e a sua finitude, a publicidade promove a ficção de um mundo ideal, no qual as disjunções entre sujeitos ou entre sujeitos e objetos são apenas simulacros. Ela é "festa, imanência, positividade"16. $\mathrm{E}$, ironicamente, campanhas como as produzidas pelo próprio Toscani, que se pretendiam rebeldes, como igualmente a de Dove, não reproduziram senão o ideário da classe dominante, da mesma forma como a novela mexicana.

Alguns anúncios polêmicos de Toscani, sob nosso viés interpretativo, caem naquilo a que ele mesmo chamou de crime de exclusão social e racismo, quando, em sua obra A Publicidade é um Cadáver que nos Sorri ${ }^{17}$, abriu por meio de hipérbole - recurso persuasivo dos mais explorados nas peças publicitárias -, uma espécie de processo de Nuremberg para julgar a publicidade prevalente. É o caso do anúncio em que um bebê da raça branca mama no seio de uma mulher negra. Afinal, como afirmou Baudrillard, "os direitos do homem se degradam à medida que prolifera o discurso dos direitos do homem"18.

Toscani, porém, continua a vangloriar sua posição em outra obra, Tchau, Mãe, quando diz:

Onde era possível encontrar a provocação no fim do século XIX? Seguramente na arte. E hoje? As vanguardas artísticas pararam de fazer escândalo. Onde está a transgressão? Paradoxalmente, na expressão mais reconhecível do capitalismo: a publicidade. Por isso, é preciso começar a olhar com atenção as mensagens da Benetton, que parecem hoje as únicas capazes de suscitar um debate na nossa sociedade $^{19}$.

Barthes nos lembra que, se o lugar-comum nos dá o poder de falar, por outro lado nos "vincula aos instrumentos do poder e consagra a divisão cultural, portanto social, das linguagens" ${ }^{20}$. E completa: "a vanguarda, em qualquer arte, é a força que rejeita o lugar-comum" ${ }^{21}$. Podemos acrescentar que o lugar-comum, o uso de "provérbios, máximas, ditos populares, expressões consagradas pelo uso" ${ }^{22}$, consiste em argumento de autoridade, sendo recurso de persuasão dos mais explorados no âmbito do enredo, do comportamento e dos diálogos dos personagens de Rebelde.

Esse conservadorismo do relvado da telenovela é explicável pelos nós de arborescências que podem ocorrer nos

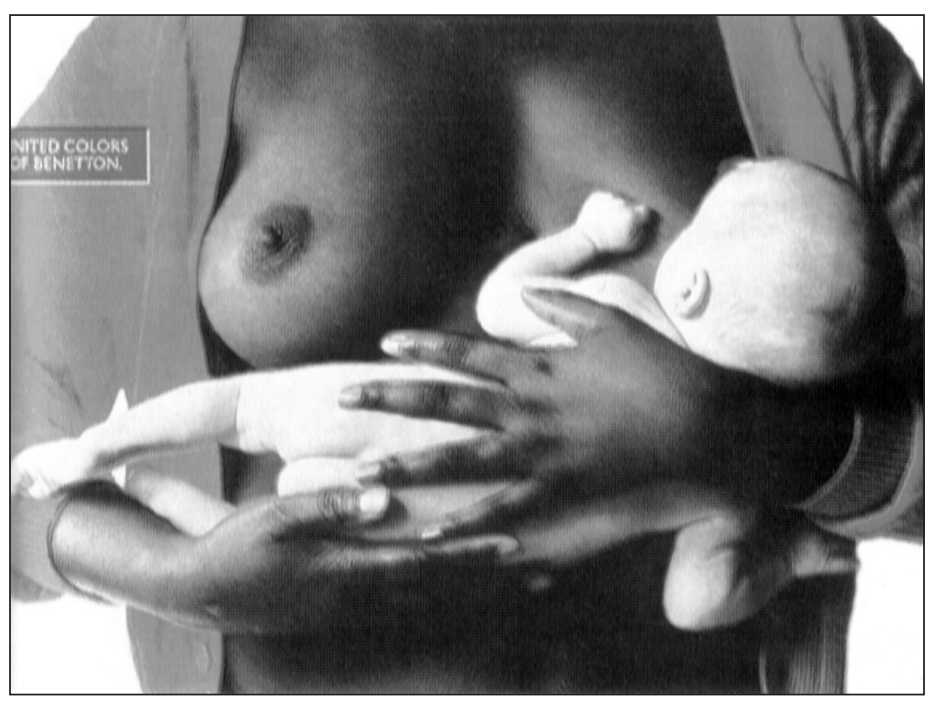

Anúncio Benneton
16. BAUDRILLARD, op cit., p. 182.

17. TOSCANI, op. cit.

18. BAUDRILLARD, Jean. Tela total. 3. ed. Porto Alegre: Sulina, 2002. p. 14. 19. TOSCANI, Oliviero. Tchau, mãe. Rio de Janeiro: Revan, 1996. p. 57.

20. BARTHES, Roland; BOUTTES, Jean-Louis. Lugares-comuns. Enciclopédia Einaudi, Lisboa: Imprensa Nacional/Casa da Moeda, 1985.

21. Ibid.

22. $\mathrm{KOCH}$, Ingedore $\mathrm{G}$. Villaça. Argumentação e linguagem. 2. ed. São Paulo: Cortez, 1987. p. 157. 
23. KATO, G. Um dia com RBD. Revista Capricho, São Paulo, n. 1001, p 90-97, set. 2006

24. OROZCO GÓMEZ Guillermo. La telenovela en México: ¿de una expresión cultural a un simple producto para la mercadotecnia? Revista Comunicación y Sociedad, Guadalajara, n. 5, p. 33, 2006. Disponível em: $<$ http://dialnet.unirioja. es/servlet/articulo?codig $\mathrm{o}=2190780>$. Acesso em: 19 maio 2007.

25. Ibid., p. 31 26. Ibid., p. 31 rizomas, como já mencionamos, igual os empuxos rizomáticos que podem dar nas raízes.

Do mesmo modo, na propaganda, as formas fixas, arbóreas, se reproduzem continuamente no tecido verbal - em ditados populares, expressões desgastadas, opiniões do senso comum etc. -, tanto quanto nos traços estereotipados dos personagens - as famílias felizes no café da manhã, as mulheres jovens e sedutoras, os homens afortunados etc.

Assim como a publicidade espetaculariza não só a vida real das celebridades, mas também o cotidiano das pessoas comuns, nos shows do RBD os integrantes, apesar de apresentados com seus nomes reais, representam os personagens e se beijam, imitando a ação dos pares românticos vividos na TV. "É como uma pequena cena de Rebelde dentro do show" ${ }^{23}$, afirmou numa entrevista a atriz Dulce Maria, que vive o papel de Roberta.

Num plano secundário de análise neste texto - o da rede semântica da telenovela -, mas que ratifica a sua concepção como uma rama publicitária, temos o seu próprio nome Rebelde, que visa acionar a poderosa carga de significação histórico-social desse termo; o nome da escola em que se desenvolve a maior parte da ação, Elite Way School, por si só sintomático do universo da classe dominante em que a narrativa se desenvolve; o nome da banda, RBD, uma corruptela da palavra Rebelde; e mesmo os títulos de suas canções - Aburrida y sola, Así soy yo, Besame sin miedo, Cariño mio, Futuro ex novio, Querer-te -, que não anunciam rebeliões nem tampouco enfrentamentos sociais, mas evidenciam unicamente um olhar do indivíduo para o próprio ego.

Como bem afirma Guillermo Orozco, escrevendo sobre as fases pelas quais passou a telenovela mexicana, em seu atual estágio, no qual Rebelde se insere, essa mercadoria cultural não é "somente um simples produto da ficção televisiva, mas todo um modelo de negócios em si mesma”" ${ }^{2}$. A telenovela não é produzida para ser vista pela audiência, mas unicamente para ser consumida, comprada. Para isso, segundo o autor, "se elimina o esforço de sedução historicamente característico da telenovela na América Latina, pelo qual se colocam em jogo diferentes elementos e artifícios de maneira mais cadenciada, para dar lugar à mera excitação ao consumo" ${ }^{25}$.

É justo nesta atual etapa mercantil que "se dá um leitmotiv à telenovela, com o qual, como na publicidade comercial, o telespectador se identifique e assim se facilite a compra do que é anunciado"26. O mesmo acontece com seus platôs, que se espalham em busca dessa identificação com o público já familiarizado ao seu espectro de valores.

Os outros platôs que, pelo princípio de conexão, se interligam à telenovela, atuam com conteúdos discursivos voltados a alimentar a excitação, a euforia, do consumo. Mas se um platô conecta-se com o outro, entre eles vicejam os nós arborescentes representados pela posição conservadora ante os valores dominantes, e o foco sempre apontado para a elite, assim como nos materiais publicitários.

A publicidade, inclusive, começa a se valer dessa estratégia de usar personagens que, como diferencial criativo, ultrapassam a narrativa ficcional e ganham a esfera do real, em que continuam ou não anunciando a marca. É 
o caso da banda de rock The Uncles, criada em 2007 para cantar um jingle e protagonizar, no Brasil, o comercial do lançamento do Sentra, sedã da marca Nissan. Formado por quatro integrantes acima dos cinqüenta anos apenas para essa finalidade, o grupo já vem compondo músicas independentes da campanha do Sentra ${ }^{27}$. Como uma rama publicitária dá origem a outra, esta se desprende daquela para gerar outro negócio.

Poderíamos também afirmar aqui que a bricolagem, forma de pensamento preponderante na elaboração do discurso publicitário, passou a ser, também, outra ferramenta para sua atuação no mercado, ao mesclar, propositalmente, representações fictícias com indivíduos verídicos.

Rebelde e seu mundo bulbar, de platôs, nos mostra que o marketing rompeu há tempos com o cosmo-raiz da cultura arborescente e vem se valendo do modelo rizotômico para espalhar o seu cosmo-relvado. Não é por acaso que se disseminam cada dia mais, pelo mundo inteiro, estratégias mercadológicas baseadas no apagamento das fronteiras entre a realidade e a ficção, e que além do mais fomentam o seu cultivo. Baudrillard nos alerta, contudo, que "a multiplicação só é positiva em nosso sistema de acumulação. Na ordem simbólica, equivale a uma subtração”"28.

Os exemplos já consagrados como os de merchandisings em telenovelas, filmes e programas televisivos, em que os produtos reais são consumidos pelos personagens, parecem sementes de uma era ultrapassada, se comparados com as novas estratégias como a do caso já consumado de Rebelde, e certamente, também, o da banda The Uncles, em progresso.

Deleuze e Guattari afirmavam que o rizoma reúne o melhor e o pior, a batata e a erva daninha. Apesar de ser como um riacho sem meio nem fim, que rói suas duas margens e adquire a velocidade no meio, apesar de ser sempre intermezzo, o rizoma de Rebelde vai pelo rumo esperado. Em suma: não é dessa vez, novamente, que se dá ao espectador - e ao consumidor - as batatas.

Resumo: Fenômeno comunicacional, a telenovela mexicana Rebelde é apenas um dos produtos de uma estratégia de marketing que se espalha por meio do conceito de rizoma cunhado por Deleuze e Guattari. No plano discursivo, todavia, o conteúdo da novela, bem como o de outros bens de sua rama, como as letras da banda RBD, apresenta-se no formato de árvore, revelando uma hierarquia típica dos discursos conservadores como o da publicidade. O presente artigo busca discutir essa estratégia mercadológica que se ramifica como rizoma, enquanto seu discurso, como o publicitário, mantém-se preso ao modelo arborescente dos valores dominantes.

Palavras-chave: Rebelde, rizoma, estratégia, marketing, publicidade.
Abstract: Communicational phenomenon, the Mexican soap opera Rebelde is only one of the products of a marketing strategy that spreads itself across the rhizome concept created by Deleuze and Guattari. From the discursive perspective, however, the content of the soap opera, as well as of other products from its frame, such as $R B D$ group songs lyrics, appears in a treeformat, revealing a hierarchy typical from conservative discourses, like the advertising one. This article discusses this marketing strategy that spreads itself like a rhizome, whereas its discourse, like the advertising one, stays tied to the arborescence model of dominant values.

Keywords: Rebelde, rhizome, strategy, marketing, advertising.
27. SILVA, Cleide; RIBEIRO, Marili. Montadoras apelam a "tiozão" e suspense para vender sedãs. O Estado de S. Paulo, São Paulo, p. B16, 17 abr. 2007.

28. BAUDRILLARD, Jean. Tela total. 3. ed. Porto Alegre: Sulina, 2002. p. 156. 